\title{
Multiphase heterogeneous catalytic enantioselective hydrogenation of acetophenone over cinchona-modified $\mathrm{Pt} / \mathrm{C}$
}

\author{
Alvise Perosa*, Pietro Tundo, Maurizio Selva \\ Dipartimento di Scienze Ambientali, Università Ca' Foscari, Dorsoduro 2137, 30123 Venezia, Italy
}

Received 5 July 2001; received in revised form 10 October 2001; accepted 12 October 2001

\begin{abstract}
The multiphase heterogeneous enantioselective hydrogenation of acetophenone in the presence of cinchona-modified Pt/C was investigated. The system demonstrated the feasibility of this reaction on non-activated ketones. The reaction proceeded selectively, at room temperature and atmospheric pressure, towards the formation of 1-phenylethanol, with up to $20 \%$ ee (enantiomeric excess) of either enantiomer depending on the modifier used. A mode of action of the modifier is proposed to account for the mechanism. A comparison with other systems indicates that the investigated system likely acts by a different mechanism, and that it is quite specific for acetophenone. () 2002 Elsevier Science B.V. All rights reserved.
\end{abstract}

Keywords: Hydrogenation; Acetophenone; Cinchona; Enantioselective; Multiphase

\section{Introduction}

Heterogeneous enantioselective catalytic reactions are quite rare. However, this field is growing since stereoselective reactions over supported metal catalysts have obvious advantages. Besides, they are Green Chemistry: in that they are intrinsically atom-economical since they produce a single enantiomer catalytically, and the catalyst is solid, i.e. separable and recyclable by filtration.

Enantiodifferentiation in the hydrogenation of activated prochiral ketones to the corresponding chiral alcohol with cinchona-modified (e.g. cinchonine, cinchonidine, and derivatives; Fig. 1) catalysts has been widely studied by Baiker and co-workers [1-5] in the case of alumina supported metals. Such catalysts were found to promote reduction and induce stereoselec-

\footnotetext{
* Corresponding author. Tel.: +39-41-257-8687; fax: +39-41-257-8620.

E-mail address: alvise@unive.it (A. Perosa).
}

tivity in the $\alpha$-carbonyl hydrogenation of pyruvates $[6,7]$, ketopentolactone [8,9], other $\alpha$-dicarbonyls [10], and, in general, on activated ketones (e.g. trifluoromethylketones) [11]. The limitations of the investigated systems were the necessity for an electron deficient carbonyl [11], and for the high $\mathrm{H}_{2}$ pressure (10-70 atm) which were usually required. In all cases careful optimisation of the conditions was necessary in order to achieve satisfactory enantiomeric excesses (ee's) $(>70 \%)$.

As far as non-activated ketones are concerned, Tungler et al. [12] reported the heterogeneous enantioselective catalytic hydrogenation of acetophenone, with $\mathrm{Pd} / \mathrm{C}$ and $S$-proline. However, the best result was a $22 \%$ ee at $78 \%$ conversion, but enantioselectivity decreased by pushing conversion.

The catalytic multiphase hydrodehalogenation (HDX) and/or hydrogenation reaction is an efficient and, most importantly, selective method for the reductive dehalogenation/hydrogenation around an aromatic ring. It can be used to efficiently remove aromatic 


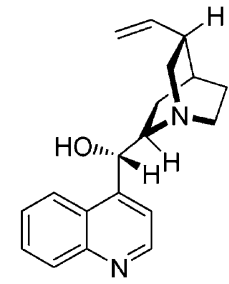

cinchonine, $\mathrm{CN}$

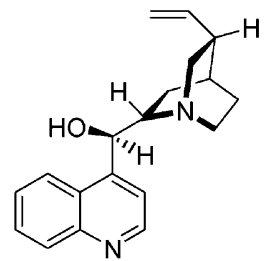

L-cinchonidine, CD
Fig. 1.

halogens (from toxic compounds such as PCBs and PCDD/PCDFs) [13-17], or to reduce aromatic carbonyls [18-21], simply by tuning the conditions. The multiphase system consists of a hydrocarbon solvent, an aqueous phase, a phase-transfer (PT) agent, a supported metal catalyst, hydrogen at atmospheric pressure, at low temperature $\left(T<50{ }^{\circ} \mathrm{C}\right)$.

The mechanism which accounts for chemoselectivity invokes the formation, over the $\mathrm{Pt} / \mathrm{C}$ or $\mathrm{Pd} / \mathrm{C}$ catalyst, of a layer made by the adsorbed PT agent (e.g. an onium salt, an amine) which modifies the catalytic environment around the metal atoms [20]. The role of the PT agent has been investigated in depth: it can be used in catalytic amount [13-20], it can be ionic (onium salts) or neutral (amines, PEGs) [19,20], it operates at mild temperatures and atmospheric pressure. Four separate phases are therefore present: solid modified catalyst, liquid organic, liquid aqueous, gaseous $\left(\mathrm{H}_{2}\right)$.

Herein, we report some preliminary results on the multiphase catalytic stereoselective hydrogenation of acetophenone to 1-phenylethanol, in the presence of a cinchona modifier. This reaction occurs in the presence of cinchonine or cinchonidine adsorbed on $\mathrm{Pt} / \mathrm{C}$ and in a multiphase system made by isooctane and water, under mild conditions (room temperature, $1 \mathrm{~atm} \mathrm{H}_{2}$ ), and using commercial reagents. Generally, ee's in the range of $5-17 \%$, and up to $20 \%$ in one case were observed. Either enantiomer could be obtained, depending on the alkaloid diastereomer used as modifier.

\section{Experimental}

\subsection{Materials}

The 5\% Pt/C catalyst (effective Pt content $4.25 \%$, particle size $325 \mathrm{mesh}$, surface area $900-1000 \mathrm{~m}^{2} / \mathrm{g}$ ) benzylcinchonidinium chloride (BCDC), Aliquat 336, acetophenone, ethyl pyruvate and trifluoroacetophenone, cinchonine 99\% (CN) and L-cinchonidine 98\% (CD) were all commercial products used as received.

GC analyses were performed using a fused silica capillary column "Chrompack CP Sil 8 CB" $(30 \mathrm{~m} \times 0.32 \mathrm{~mm})$ with $95 \%$ dimethyl-5\% diphenyl polysiloxane as the stationary phase (film thickness $0.25 \mu \mathrm{m}$ ); in all cases decane was used as the internal standard. GC/MS analyses were performed on an HP 5971 mass detector coupled to an HP 5890 gas chromatograph fitted with a $30 \mathrm{~m} \times 0.25 \mathrm{~mm}$ DB5 capillary column. Enantiomeric enrichment was measured by chiral GC analyses using a fused silica capillary column "HP Chiral" $(30 \mathrm{~m} \times 0.25 \mathrm{~mm})$ with $20 \%$ permethylated cyclodextrin as the stationary phase (film thickness $0.25 \mathrm{~mm}$ ). Optical rotation was measured on a Perkin Elmer 241 polarimeter.

Enantiomeric excess was defined: ee $(\%)=100 \times$ $|R-S| /(R+S)$.

\subsection{Catalyst pretreatment}

For the preparation of the $\mathrm{CD}: \mathrm{Pt} / \mathrm{C}$ preadsorbed catalyst, respectively, 50, 100, 140, 200, $300 \mathrm{mg}$ of CD were dissolved in $5 \mathrm{ml}$ of absolute ethanol, $200 \mathrm{mg}$ of $5 \% \mathrm{Pt} / \mathrm{C}$ were added (CD:Pt/C weight ratio: 0.25, 0.50, $0.70,1.00,1.50$, respectively), and the suspension sonicated for $5 \mathrm{~min}$. After centrifuging $(3000 \mathrm{rpm})$ for $10 \mathrm{~min}$, and decanting, the solid was dried under vacuum $\left(10^{-3}\right.$ Torr $)$ at room temperature for $2 \mathrm{~h}$.

\subsection{Hydrogenation experiments}

In all cases, hydrogen was bubbled in the reaction mixture, stirred at $1000 \mathrm{rpm}$, with an approximate flow rate of $5 \mathrm{ml} / \mathrm{min}$.

Hydrogenation reactions (Table 1) were run in a $25 \mathrm{ml}$ three-necked $\left(\mathrm{H}_{2}\right.$ bubbler, reflux condenser, sampling septum) jacketed reactor thermostated at $50{ }^{\circ} \mathrm{C}$, loaded with, in this order: $84 \mathrm{mg}(0.7 \mathrm{mmol})$ of acetophenone, $10 \mathrm{ml}$ of isooctane, $85 \mathrm{mg}$ of $\mathrm{Pt} / \mathrm{C}$, $70 \mathrm{mg}$ of cinchona alkaloid (CN, CD, BCDC) and $5.5 \mathrm{ml}$ of water $(5 \% \mathrm{KOHaq}$ in one case). The stereoselective reduction of acetophenone on a preparative scale (Table 1, run 3 ) was run in a $250 \mathrm{ml}$ three-necked reactor under the same conditions for $69 \mathrm{~h}$. Distillation of the residue yielded $1.25 \mathrm{~g}$ (80\%) of 1-phenylethanol 
Table 1

Enantioselective hydrogenation of $\mathbf{1}$ in a multiphase system catalysed by $\mathrm{Pt} / \mathrm{C}$, with $\mathrm{H}_{2}$, in the presence of different chiral modifiers (conditions: $0.7 \mathrm{mmol}$ substrate in $10 \mathrm{ml}$ isooctane, $5.5 \mathrm{ml}$ aqueous phase, $85 \mathrm{mg} \mathrm{Pt} / \mathrm{C} 5 \%(3 \mathrm{~mol} \%), \mathrm{CN}$ and $\mathrm{CD} 70 \mathrm{mg}(35 \mathrm{~mol} \%), 50{ }^{\circ} \mathrm{C}$, $1 \mathrm{~atm} \mathrm{H}_{2}$ )

\begin{tabular}{|c|c|c|c|c|c|c|c|c|}
\hline & \multirow[t]{2}{*}{ Chiral modifier/s } & \multirow[t]{2}{*}{ Time (min) } & \multirow[t]{2}{*}{$\mathrm{KOH}(\%)$} & \multirow[t]{2}{*}{ Substrate $(\%)$} & \multicolumn{4}{|c|}{ Products ( $\%$ by GC) } \\
\hline & & & & & 2 & ee & 3 & 4 \\
\hline 1 & $\mathrm{CN}$ & 80 & 5 & 0 & 100 & 0 & - & - \\
\hline 2 & $\mathrm{CN}$ & 120 & 0 & 75 & 25 & $5(R)$ & - & - \\
\hline 3 & $\mathrm{CD}$ & 180 & 0 & 58 & 39 & $7(S)$ & 2 & 1 \\
\hline $4^{\mathrm{a}}$ & $\mathrm{CN}$ & 4140 & 0 & 8 & 92 & $5(R)$ & - & - \\
\hline 5 & $\mathrm{BCDC}^{\mathrm{b}}$ & 360 & 0 & 50 & 40 & 0 & 5 & 5 \\
\hline 6 & CN/A336 $6^{\mathrm{c}}$ & 296 & 5 & 92 & 7 & n.d. & 1 & 0 \\
\hline
\end{tabular}

${ }^{\text {a }}$ Run on preparative scale $(\times 10)$ : yield of $2=1.25 \mathrm{~g}(80 \%)$ distilled, $[\alpha]_{\mathrm{D}}^{20}=+1.95^{\circ}$ (neat).

${ }^{\mathrm{b}} \mathrm{BCDC}, 70 \mathrm{mg}=25 \mathrm{~mol} \%$.

${ }^{\mathrm{c}} \mathrm{A} 336,22 \mathrm{mg}=8 \mathrm{~mol} \%$.

(GC-MS identical to a commercial sample), $[\alpha]_{\mathrm{D}}^{20}=$ $+1.95^{\circ}$ (neat), ee $=5 \%,(R)-(+)-1$-phenylethanol [22].

Hydrogenation reactions (Table 2) were run in a $25 \mathrm{ml}$ three-necked flask loaded with, in this order: $84 \mathrm{mg}(0.7 \mathrm{mmol})$ of acetophenone, $10 \mathrm{ml}$ of isooctane, $120 \mathrm{mg}$ of the preadsorbed CD:Pt/C catalysts (CD:Pt/C weight ratio: $0.25,0.50,0.70,1.00,1.50$, respectively), and $5.5 \mathrm{ml}$ of water. For entry 7 , where $p \mathrm{H}_{2}=30 \mathrm{~atm}$, the reaction was run in a sealed steel autoclave provided with a glass liner.

In a $25 \mathrm{ml}$ three-necked flask were loaded (Table 3, entry 1$)$, in this order: $83 \mathrm{mg}(0.7 \mathrm{mmol})$ of ethyl pyruvate, $10 \mathrm{ml}$ of isooctane, $120 \mathrm{mg}$ of the preadsorbed $\mathrm{CD}: \mathrm{Pt} / \mathrm{C}$ catalyst (CD:Pt/C weight ratio: 0.50$)$, and $5.5 \mathrm{ml}$ of water. After $0.5 \mathrm{~h}$ at room temperature, $100 \%$ conversion to ethyl lactate was observed by GC, with $14 \%$ ee.

In a $25 \mathrm{ml}$ three-necked flask were loaded (Table 3, entry 2), in this order: $127 \mathrm{mg}(0.7 \mathrm{mmol})$ of $2,2,2$ trifluoroacetophenone, $10 \mathrm{ml}$ of isooctane, $120 \mathrm{mg}$ of the preadsorbed $\mathrm{CD}: \mathrm{Pt} / \mathrm{C}$ catalyst $(\mathrm{CD}: \mathrm{Pt} / \mathrm{C}$ weight ratio: 0.50 ), and $5.5 \mathrm{ml}$ of water. After $4 \mathrm{~h}$ at room temperature, $100 \%$ conversion to 2,2,2-trifluoro-1phenylethanol was observed by GC, with $4 \%$ ee.

In a $50 \mathrm{ml}$ glass liner were loaded (Table 3 , entry 3 ), in this order: acetophenone $(4.8 \mathrm{~g}, 0.04 \mathrm{~mol}), 7.5 \mathrm{ml}$ $\mathrm{EtOH}, \mathrm{Pt} / \mathrm{C} 5 \%(0.05 \mathrm{~g})$ and $\mathrm{CD}(0.01 \mathrm{~g})$, and the suspension was sonicated for $5 \mathrm{~min}$. The liner was placed in a sealed steel autoclave and charged with $70 \mathrm{~atm}$ $\mathrm{H}_{2}$. After $16 \mathrm{~h}, 72 \%$ conversion of acetophenone to 1-phenylethanol was measured by GC, with $3 \%$ ee.

Table 2

Enantioselective hydrogenation of $\mathbf{1}$ in a catalytic multiphase system, in the presence of $\mathrm{CD}$ preadsorbed on $\mathrm{Pt} / \mathrm{C}$, at $25{ }^{\circ} \mathrm{C}$ (conditions: $0.7 \mathrm{mmol}$ substrate in $10 \mathrm{ml}$ isooctane, $5.5 \mathrm{ml}$ neutral aqueous phase, $25^{\circ} \mathrm{C}, 1 \mathrm{~atm} \mathrm{H}_{2}$, CD preadsorbed on $\mathrm{Pt} / \mathrm{C} 5 \%(3 \mathrm{~mol} \%)$ )

\begin{tabular}{|c|c|c|c|c|c|c|c|c|}
\hline & \multirow[t]{2}{*}{$\mathrm{CD}: \mathrm{Pt} / \mathrm{C}(\mathrm{mol} \% \mathrm{CD})$} & \multirow[t]{2}{*}{ Time $(\min )$} & \multirow[t]{2}{*}{ Substrate $(\%)$} & \multicolumn{5}{|c|}{ Products ( $\%$ by GC) } \\
\hline & & & & 2 & ee $(\%)$ & 3 & ee & 4 \\
\hline 1 & $1.5(42)$ & 300 & 75 & 25 & $5(S)$ & - & & - \\
\hline 2 & $1.0(21)$ & 300 & 71 & 27 & $9(S)$ & 1 & n.d. & 1 \\
\hline 3 & $0.7(20)$ & 300 & 74 & 24 & $17(S)$ & 1 & n.d. & 1 \\
\hline 4 & $0.5(15)$ & 300 & 55 & 45 & $20(S)$ & - & & - \\
\hline 5 & $0.25(14)$ & 300 & 22 & 76 & $15(S)$ & 1 & & 1 \\
\hline $6^{\mathrm{a}}$ & $0.7(20)$ & 422 & 68 & 23 & $14(S)$ & 7 & n.d. & 2 \\
\hline $7^{b}$ & $0.5(15)$ & 300 & 90 & 10 & 0 & - & & - \\
\hline
\end{tabular}

\footnotetext{
${ }^{\text {a }} T=50^{\circ} \mathrm{C}$.

b $\mathrm{pH}_{2}=30 \mathrm{~atm}$.
} 
Table 3

Heterogeneous enantioselective catalytic hydrogenation at $25^{\circ} \mathrm{C}$, comparison data

\begin{tabular}{|c|c|c|c|c|c|c|c|}
\hline & Substrate & Catalyst & Conditions & Time (h) & Conversion $(\%)$ & Product & ee $(\%)$ \\
\hline 1 & Ethyl pyruvate & $\mathrm{CD}: \mathrm{Pt} / \mathrm{C}(1: 2)$ & Multiphase $^{\mathrm{a}}, 1 \mathrm{~atm} \mathrm{H}_{2}$ & 0.5 & 100 & $\mathrm{CH}_{3} \mathrm{CH}(\mathrm{OH}) \mathrm{CO}_{2} \mathrm{Et}$ & 14 \\
\hline 2 & $\mathrm{PhCOCF}_{3}$ & $\mathrm{CD}: \mathrm{Pt} / \mathrm{C}(1: 2)$ & Multiphase $^{\mathrm{a}}, 1 \mathrm{~atm} \mathrm{H}_{2}$ & 4 & 100 & $\mathrm{PhCH}(\mathrm{OH}) \mathrm{CF}_{3}$ & 4 \\
\hline 3 & 1 & $\mathrm{CD}+\mathrm{Pt} / \mathrm{C}$ & $\mathrm{EtOH}^{\mathrm{b}}, 70 \mathrm{~atm} \mathrm{H}_{2}$ & 16 & 72 & $\mathrm{PhCH}(\mathrm{OH}) \mathrm{CH}_{3}$ & 3 \\
\hline 4 & 1 & $\mathrm{CD}: \mathrm{Pt} / \mathrm{Al}_{2} \mathrm{O}_{3}(1: 2)$ & Multiphase $^{\mathrm{a}}, 1 \mathrm{~atm} \mathrm{H}_{2}$ & 24 & 0 & - & - \\
\hline
\end{tabular}

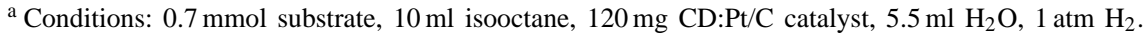

${ }^{\mathrm{b}}$ Conditions: $0.04 \mathrm{~mol} \mathrm{1,} 7.5 \mathrm{ml} \mathrm{EtOH}, 0.05 \mathrm{~g} \mathrm{Pt} / \mathrm{C}, 0.01 \mathrm{~g} \mathrm{CD}, 70 \mathrm{~atm} \mathrm{H}_{2}$ [3].

In a $25 \mathrm{ml}$ three-necked flask were loaded (Table 3, entry 4), in this order: acetophenone $(84 \mathrm{mg}, 0.7$ $\mathrm{mmol}), 10 \mathrm{ml}$ of isooctane, $120 \mathrm{mg}$ of the preadsorbed $\mathrm{CD}: \mathrm{Pt} / \mathrm{Al}_{2} \mathrm{O}_{3}$ catalyst $\left(\mathrm{CD}: \mathrm{Pt} / \mathrm{Al}_{2} \mathrm{O}_{3}\right.$ weight ratio: 0.50 , prepared analogously to $\mathrm{CD}: \mathrm{Pt} / \mathrm{C})$, and $5.5 \mathrm{ml}$ of water. After $24 \mathrm{~h}$ at room temperature no reaction was observed.

\section{Results}

The investigated model reaction was the catalytic hydrogenation of acetophenone 1 to 1-phenylethanol 2 with $\mathrm{H}_{2}$, over a commercial $\mathrm{Pt} / \mathrm{C}$ modified by a chiral modifier, in a biphasic water-isooctane system:

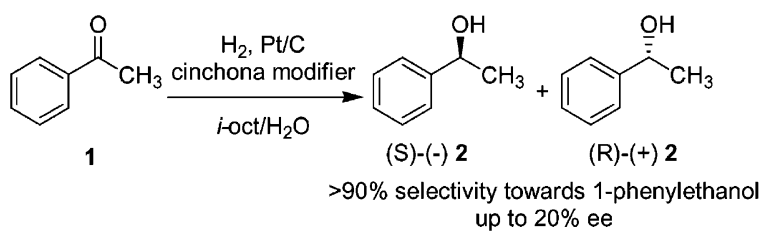

The chiral modifiers employed were $\mathrm{CN}, \mathrm{CD}$, and BCDC. Table 1 shows the results of the hydrogenation of 1 with different chiral modifiers, under the standard conditions employed in previous studies [20]. Reaction times were determined by monitoring the reactions via GC. Enantioselectivity was measured by chiral GC.

A comparison made using $\mathrm{CN}$ both with and without $\mathrm{KOH}$ in the aqueous phase (runs 1 and 2, respectively), showed that $\mathrm{KOH}$ accelerates the reaction, but is detrimental to ee. All of the subsequent experiments were run without $\mathrm{KOH}$. The reaction in entry 2, run with $\mathrm{CN}$, yielded $5 \%$ ee of the $R$ stereoisomer, while the hydrogenation in entry 3 was run with $C D$ under the same conditions of entry 2, and yielded $7 \%$ ee of the $S$ stereoisomer. Run 4 is a repetition of run 2 on a preparative scale: product $\mathbf{2}$ was purified and its ee measured by polarimetry and used to confirm the ee determined thereafter by chiral GC; this experiment also allowed to determine the absolute stereochemistry of the product. The ee's were up to $5 \%$, and the chemoselectivity toward 2 was high (>95\%).

The chemoselectivity of the reaction with BCDC (run 5) on the other hand, was poorer (89\%), yielding ring reduction products $\mathrm{CyCH}(\mathrm{OH}) \mathrm{CH}_{3} \mathbf{3}$ and $\mathrm{CyCOCH}_{3} 4$ along with 2, and no enantiomeric enrichment. Coupling a PT agent such as Aliquat 336 (A336) with the chiral modifier was also detrimental (run 6), the reaction appeared inhibited, even after adding $5 \% \mathrm{KOH}$ to the mixture.

A series of experiments was run with the aim to improve ee's for the reaction $\mathbf{1} \rightarrow \mathbf{2}$, using $\mathrm{CD}$ as the chiral modifier. To ensure reproducibility $\mathrm{CD}$ was preadsorbed on $\mathrm{Pt} / \mathrm{C}$, by a procedure that involved sonication. The tabulated reaction times were standardised at $5 \mathrm{~h}$ to compare reaction rates. However, all reactions were followed to complete conversion in order to ensure that chemoselectivity towards 2 persisted. This guaranteed that ee's were always independent on conversion. The results are reported in Table 2.

Entries 1-5 refer to the reduction of 1 run with progressively decreasing loads of $\mathrm{CD}$ adsorbed on the $\mathrm{Pt} / \mathrm{C}$ catalyst. Increasing amounts of chiral modifier slowed the reaction (Fig. 2A). Enantioselectivity was sensitive to the amount of $\mathrm{CD}$, and a maximum of $20 \%$ ee was reached when a 1:2 ratio of $\mathrm{CD}: \mathrm{Pt} / \mathrm{C}$ was used, as can be seen by the plot of ee vs. CD:Pt/C (Fig. 2B). By increasing or reducing the amount of $\mathrm{CD}$, enantioselectivity decreased.

The reaction run at higher temperature $\left(50^{\circ} \mathrm{C}\right.$, run 6) was slightly faster, but less chemo- (7\% of $\mathbf{3}$ 


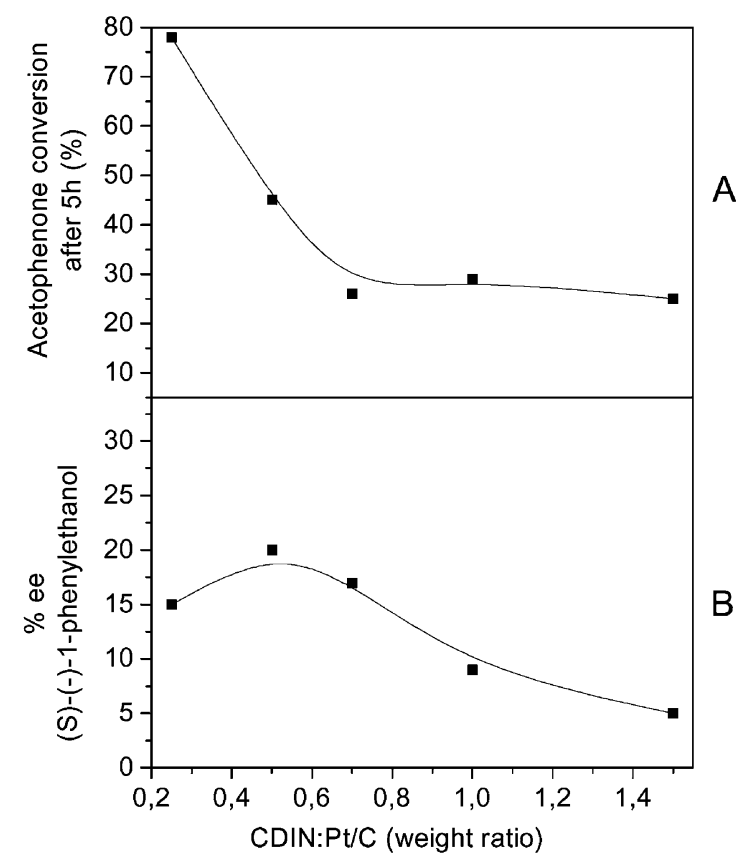

Fig. 2. Effect of varying amounts of $\mathrm{CD}$ on the conversion (A) and enantioselectivity (B) of reaction $\mathbf{1} \rightarrow \mathbf{2}$.

was formed) and enantioselective (ee $=14 \%$ ), than the corresponding reaction run at room temperature (run 3). Notably, by applying $\mathrm{H}_{2}$ pressure (30 bar, run 7 ), both rate and enantioselectivity were strongly suppressed.

A series of experiments were run to compare this multiphase heterogeneous enantioselective hydrogenation system with others $[3,11]$. The results are shown in Table 3.

By using the same multiphase conditions of entry 4 of Table 2, activated substrates such as ethyl pyruvate and trifluoroacetophenone were readily hydrogenated (entries 1 and 2, 100\% conversion after $30 \mathrm{~min}$ and $4 \mathrm{~h}$, respectively). The enantioselectivities (ee $=14$ and $4 \%$, respectively), however, were poorer than for acetophenone (ee $=20 \%$ ) under the same conditions.

Under the conditions reported by Baiker and co-workers [3], using $\mathrm{H}_{2}$ pressure in ethanol solvent, the catalytic reduction of acetophenone with $\mathrm{CD}-\mathrm{Pt} / \mathrm{C}$ system yielded $72 \%$ of phenylethanol after $16 \mathrm{~h}$, with $3 \%$ ee (entry 3 ).

Finally, by using an alumina (instead of charcoal) supported Pt catalyst (entry 4), under the same experimental conditions for the enantioselective reduction of acetophenone (run 4 of Table 2), no reaction whatsoever was observed.

\section{Discussion}

Initially, different chiral modifiers were tested for the $\mathrm{Pt} / \mathrm{C}$ reduction of $\mathbf{1}$. The main results reported in Table 1 were the following:

1. A non-activated substrate such as $\mathbf{1}$ could be hydrogenated stereoselectively with cinchona-modified $\mathrm{Pt} / \mathrm{C}$, thereby providing evidence against the postulate that electron deficient ketones were required [11].

2. $\mathrm{CN}$ and $\mathrm{CD}$ were the most promising modifiers for the enantioselective hydrogenation. The modifier bearing a quaternary nitrogen (BCDC) was detrimental to enantioselectivity, in agreement with the observation that the stereo-inducing site of the cinchona alkaloids is the quinaclidine nitrogen, which coordinates to the reactive carbonyl [1]. By masking this nitrogen with an additional alkyl group, coordination was precluded and therefore enantiodifferentiation as well.

3. By switching between $\mathrm{CN}$ and $\mathrm{CD}$ opposite enantioselectivities could be obtained, providing access to either enantiomer: $\mathrm{CN}$ favoured formation of $(R)-(+) \mathbf{2}$, instead CD favoured $(S)-(-) \mathbf{2}$.

Enantioselectivity appeared to be independent on conversion, indicating that the modified catalyst maintains its efficiency throughout the reaction.

$\mathrm{CD}$ was then chosen to test the effect of varying $\mathrm{CD}: \mathrm{Pt} / \mathrm{C}$ ratios. This parameter proved critical for enantioselectivity (Table 2). As shown in Fig. 2A, the highest ee (20\%, run 4) was reached for CD:Pt/C = 0.5 , which corresponded to approximately $15 \mathrm{~mol} \%$ of $\mathrm{CD}$ and $3 \mathrm{~mol} \%$ of $\mathrm{Pt}$ respect to $\mathbf{1}$.

A tentative explanation was that when used in this amount, $\mathrm{CD}$ formed a monolayer over the $\mathrm{Pt} / \mathrm{C}$ surface, with prochiral cavities capable of enantiodifferentiation. The arrangement of $\mathrm{CD}$ on a Pt surface was explored by Thomas using computer graphics, who suggested that $\mathrm{CD}$ formed an ordered, well spaced array of interstices in the sorbed layer [23]. As shown in Fig. 2, by using lower amounts of CD the reaction rate increased while ee's decreased, very likely implying that the cavities were wider and more 
accessible (looser) but therefore less stereo-efficient. While, a larger amount of CD formed multilayers which restricted access of $\mathbf{1}$ to the catalytic site, and the reaction rate and enantioselectivity decreased.

This kind of justification may have also accounted for the effect of $\mathrm{KOH}$, which was shown to accelerate the reaction but to depress enantioselectivity (Table 1). $\mathrm{KOH}$ likely acted by removing the $\mathrm{CN}$ or $\mathrm{CD}$ adsorbed on the catalyst surface, and a cleaner catalyst meant faster reaction but poorer stereoselectivity in our case.

A higher temperature had a predictable effect (run 6): it accelerated the reaction but lowered stereoselectivity.

A higher $\mathrm{H}_{2}$ pressure (30 atm, run 7) drastically reduced both the hydrogenation rate and the enantioselectivity, likely because $\mathrm{H}_{2}$ disturbed the arrangement of $\mathrm{CD}$ on the catalyst. Hydrogen pressure, therefore, seemed to have an effect opposite to the one reported by Baiker and co-workers [8] in the hydrogenation of ethyl pyruvate and ketopentolactone.

It should be noted that the hydrogenation was satisfactory and reproducible when the preadsorbed $\mathrm{CD}: \mathrm{Pt} / \mathrm{C}$ catalysts were prepared by sonicating the $\mathrm{CD}$ solution which contained the Pt/C. Otherwise the reactions were slower if not inhibited. This effect was not totally clear but explained with the breakdown by sonication of $\mathrm{Pt} / \mathrm{C}$ aggregates.

In order to compare the enantioselective hydrogenation with the $\mathrm{CD}: \mathrm{Pt} / \mathrm{C}$ catalyst with the corresponding reaction using other cinchona-modified $\mathrm{Pt}$ hydrogenation systems, CD:Pt/C was used in the multiphase hydrogenation of ethyl pyruvate and trifluoroacetophenone, two substrates which were reported to undergo the enantioselective hydrogenation with the $\mathrm{CD}: \mathrm{Pt} / \mathrm{Al}_{2} \mathrm{O}_{3}$ catalyst in one phase (with 75 and $70 \%$ ee, respectively) [3,11]. In the CD:Pt/C multiphase system, both substrates (Table 3 , runs 1-2) were rapidly reduced quantitatively to the corresponding alcohol, but with ee's lower than the ones reported in a single phase (14 and $4 \%$ ee, respectively). The fact that only $14 \%$ ee was obtained in the multiphase hydrogenation of ethyl pyruvate with $\mathrm{CD}: \mathrm{Pt} / \mathrm{C}$ - as opposed to the high ee's reported with the $\mathrm{CD}: \mathrm{Pt} / \mathrm{Al}_{2} \mathrm{O}_{3}$ catalyst-indicated that the mechanism is likely different and that there is a margin for improvement in the enantioselective hydrogenation of 1 with $\mathrm{Pt} / \mathrm{C}$. It should also be noted that no efforts were made until now to optimise a number of parameters which have a marked influence on stereoselectivity: catalyst preparation, catalyst pretreatment, substrate purification and concentration, type of solvent/s, type of cinchona modifier. Therefore, from the first results here reported, the present $\mathrm{Pt} / \mathrm{C}$ based multiphase system appeared quite specific for the enantioselective reduction of acetophenone.

This was indirectly confirmed by two more observations. (1) The reduction of acetophenone with $\mathrm{Pt} / \mathrm{C}$ and $\mathrm{CD}$ in ethanol at 70 atm (Table 3, entry 3, the conditions for the $75 \%$ ee hydrogenation of ethyl pyruvate [3]), yielded a very poor enantioselectivity (3\% ee at $72 \%$ conversion after $16 \mathrm{~h}$ ). (2) The reduction of acetophenone with $\mathrm{CD}: \mathrm{Pt} / \mathrm{Al}_{2} \mathrm{O}_{3}$ in the multiphase conditions was totally inhibited (Table 3 , entry 4 ).

\section{Conclusions}

The multiphase enantioselective hydrogenation of acetophenone demonstrated the potential of cinchona-modified $\mathrm{Pt} / \mathrm{C}$ for the synthesis of chiral non-racemic alcohols from non-activated ketones. The ee's were still low, but up to $20 \%$ in one case. The results allowed to conclude that the modifier acted by covering the supported catalyst and forming chiral pockets which stereo-recognised the substrate and promoted enantioselectivity. However, the mechanism which takes place with $\mathrm{Pt} / \mathrm{C}$ and the water-organic phase was likely different from that using $\mathrm{Pt} / \mathrm{Al}_{2} \mathrm{O}_{3}$ and a single liquid phase, mainly because higher $\mathrm{H}_{2}$ pressure was detrimental, and because the hydrogenation of ethyl pyruvate yielded poorer ee's.

The studied reaction appears susceptible for improvement, and in particular, additional studies are been carried out to probe the effect of the catalyst, of its preparation and pretreatment, of type of substrate and its purification and concentration, of the types of solvent/s, and of the cinchona modifier.

\section{Acknowledgements}

The authors gratefully acknowledge financial support from the Università Ca' Foscari, from NATO Collaborative Linkage Grant no. EST.CLG.977159, and from the Consorzio Interuniversitario "la Chimica per l'Ambiente". 


\section{References}

[1] T. Burgi, Z. Zhou, N. Kunzle, T. Mallat, A. Baiker, J. Catal. 183 (1999) 405

[2] J.T. Wehrli, A. Baiker, D.M. Monti, H.U. Blaser, J. Mol. Catal. 49 (1989) 195.

[3] J.T. Wehrli, A. Baiker, D.M. Monti, H.U. Blaser, H.P. Jalett, J. Mol. Catal. 57 (1989) 245.

[4] T. Mallat, Z. Bodnar, B. Minder, K. Borszeky, A. Baiker, J. Catal. 168 (1997) 183.

[5] A. Baiker, J. Mol. Catal. A 115 (1997) 473.

[6] M. Schürch, T. Heinz, R. Aeschimann, T. Mallat, A. Pfaltz, A. Baiker, J. Catal. 173 (1998) 187.

[7] D. Ferri, T. Bürgi, K. Borszeky, T. Mallat, A. Baiker, J. Catal. 193 (2000) 139.

[8] M. Schürch, O. Schwalm, T. Mallat, J. Weber, A. Baiker, J. Catal. 169 (1997) 275.

[9] M. Schürch, N. Künzle, T. Mallat, A. Baiker, J. Catal. 176 (1998) 569.

[10] N. Künzle, A. Szabo, M. Schürch, G. Wang, T. Mallat, A. Baiker, J. Chem. Soc., Chem. Commun. (1998) 1377 .
[11] M. von Arx, T. Mallat, A. Baiker, J. Catal. 193 (2000) 161. [12] A. Tungler, T. Tarnai, T. Máthé, J. Petró, J. Mol. Catal. 67 (1991) 277.

[13] C.A. Marques, M. Selva, P. Tundo, J. Chem. Soc., Perkin Trans. 1 (1993) 529.

[14] C.A. Marques, M. Selva, P. Tundo, J. Org. Chem. 58 (1993) 5256.

[15] C.A. Marques, M. Selva, P. Tundo, J. Org. Chem. 59 (1994) 3830.

[16] C.A. Marques, O. Rogozhnikova, M. Selva, P. Tundo, J. Mol. Catal. A 96 (1995) 301.

[17] A. Perosa, M. Selva, P. Tundo, S.S. Zinovyev, Appl. Catal. B 32 (2001) L1.

[18] C.A. Marques, M. Selva, P. Tundo, J. Org. Chem. 60 (1995) 2430.

[19] M. Selva, P. Tundo, A. Perosa, J. Org. Chem. 63 (1998) 3266.

[20] A. Perosa, M. Selva, P. Tundo, J. Org. Chem. 64 (1999) 3934.

[21] P. Tundo, S. Zinovyev, A. Perosa, J. Catal. 196 (2000) 330.

[22] $(R)$-(+)-1-phenylethanol $\geq 99 \%[\alpha]_{\mathrm{d}}^{20}=+42^{\circ}$ (neat), Aldrich Chemical Co. Catalogue No. 2000-01.

[23] J.M. Thomas, Angew. Chem. Int. Ed. Engl. Adv. Mater. 28 (1989) 1079. 